Article

\title{
Investigation of Surface Modification of Polystyrene by a Direct and Remote Atmospheric-Pressure Plasma Jet Treatment
}

\author{
Alenka Vesel *(D) and Gregor Primc ${ }^{(1)}$ \\ Department of Surface Engineering, Jozef Stefan Institute, Jamova Cesta 39, 1000 Ljubljana, Slovenia; \\ gregor.primc@ijs.si \\ * Correspondence: alenka.vesel@guest.arnes.si
}

Received: 8 May 2020; Accepted: 25 May 2020; Published: 26 May 2020

\begin{abstract}
Localized functionalization of polymer surface with an atmospheric-pressure plasma jet was investigated at various treatment conditions. Polystyrene samples were treated with the plasma jet sustained in argon under direct or remote conditions. The two-dimensional evolution of surface wettability and the spot size of the treated area was determined systematically by measuring apparent water contact angles. Modification of surface chemistry and the formation of functional groups were investigated by X-ray photoelectron spectroscopy (XPS). The saturation of surface wettability and functional groups was observed even after a second of treatment providing the sample was placed close to the exhaust of the discharge tube. The spot diameter of the modified area increased logarithmically with increasing treatment time. However, it decreased linearly when increasing the distance. At the edge of the glowing plasma, however, the modification of surface properties was more gradual, so even $30 \mathrm{~s}$ of treatment caused marginal effects. With a further increase in the distance from the edge of the glowing plasma, however, there were no further treatment effects. The results are explained by significant axial as well as radial gradients of reactive species, in particular hydroxyl radicals.
\end{abstract}

Keywords: atmospheric-pressure plasma jet; direct and remote treatment; polystyrene; wettability patterns; mapping; functional groups; XPS

\section{Introduction}

The modification of surface properties of polymers has attracted significant attention from the scientific community because of numerous applications. A commonly used technique for tailoring surface properties of polymer materials is treatment by gaseous plasma. Plasma can be sustained at different pressures. Low-pressure plasma is characterized by its uniformity in a large volume, high dissociation fraction of gaseous molecules, and relatively low power density. Opposite to low-pressure plasmas, the atmospheric pressure plasmas are limited to a rather small volume, where a large electric field is present and also the power density is much larger. Atmospheric pressure plasmas are also characterized by large gradients in reactive particles' density. Apart from reactive plasma species, atmospheric-pressure plasmas may be rather intensive sources of ultraviolet (UV) and/or vacuum ultraviolet (VUV) radiation [1]. Gaseous plasma at atmospheric pressure can be sustained in the air or any other reactive gas, but the preferred configuration employs noble gases. Other reactive gases such as oxygen can be added in small concentrations to enhance the surface chemistry. The key advantage of noble gases is the lack of channels for the loss of the electrons' energy, such as rotational and vibrational excitation. Apart from elastic processes, the only possible ways of using electron energy are the excitation of metastables, ionization, and excitation of radiative states. On the other 
hand, electrons in plasmas sustained in molecular gases suffer numerous collisions that result in the loss of their energy, e.g., dissociation and excitation of ro-vibrational states. The molecular radicals are often recombined or relaxed at three-body collisions, which lead to the increased kinetic energy of colliding particles. The kinetic energy is shared with other molecules at collisions; therefore, the gas temperature is increased. Practically the entire discharge power in atmospheric-plasma sources is spent for gas heating.

The most commonly used atmospheric-pressure plasmas are dielectric-barrier discharges (DBD) and atmospheric-pressure plasma jets (APPJ). DBD plasmas can ensure surface modification of large areas of objects of a simple shape such as foils, whereas APPJ plasmas are better for local treatment of small areas or for treatment of the objects of a more complex shape. Typical diameters of such jets are of the order of several $\mathrm{mm}$, while some authors also reported microjets [2-4]. Such a microjet may produce a highly concentrated plasma that causes significant etching of polymers. For example, Guo et al. reported the etching rate of several $\mu \mathrm{m} / \mathrm{min}$ [3]. The length of the jet stretching from the discharge tube depends on the gas flow and the surrounding atmosphere, as well as properties of the power supply. Such jets will cause localized surface modification of a polymer sample. The modified surface area will be limited to the spot achieved by reactive gaseous species and UV/VUV radiation. Although several investigations of the surface modification of polymers by atmospheric plasma jets have already been performed [5-8], only a few papers have investigated in detail the surface finish versus treatment parameters [9-12].

Nishime et al. investigated the modified area of polyethylene terephthalate exposed to helium APPJ with a small admixture of $\mathrm{O}_{2}$ using different treatment conditions [12]. They employed a dielectric barrier discharge for the ignition of plasma streamers, which propagated downstream a flexible plastic tube allowing the treatment of samples at various angles. An additional plasma plume could be sustained at the end of the long flexible tube. The spreading area of the footprint of reactive oxygen species (ROS) on the starch-iodine-agar plates was measured. The spreading area of reactive oxygen species was increasing with increasing exposure time. Significant improvement in the wettability of the polymer was observed. The spot size of improved wettability decreased with an increasing distance from the exhaust of the flexible tube. At a distance of $5 \mathrm{~mm}$, the spot size was approximately $700 \mathrm{~mm}^{2}$, which is much more than a spot diameter caused by reactive oxygen species. The substrate holder was either grounded or left at a floating potential. If the sample was at floating conditions, the spot size was smaller for about $30-50 \%$ depending on the distance of the sample from the flexible tube. UV and VUV irradiation profiles were also determined. VUV radiation was focused in a very small area of a dimension close to the diameter of the discharge tube. However, a much larger irradiated area was observed for UV radiation. The spot size of the increased wettability on the PET surface was much larger than the footprint of either ROS, UV, or VUV irradiation measured on starch-iodine-agar plates. The area of high hydrophilicity was fairly spherical at incidence angles of 90 and $45^{\circ}$, but it was shortened in one dimension at the incidence angle of $0^{\circ}$, i.e., plasma jet parallel to the sample.

The results show that VUV photons and reactive oxygen species, such as $\mathrm{O}$ atoms, $\mathrm{O}_{3}, \mathrm{O}_{2}(\mathrm{a})$, and $\mathrm{OH}$ molecules are the key species in APPJ; therefore, it is important to know their fluxes as well as radial and axial gradients of their densities. $\mathrm{He} / \mathrm{O}_{2}$ APPJ has been well characterized by Ellerweg et al. [13]. Absolute $\mathrm{O}$-atom densities up to about $5 \times 10^{21} \mathrm{~m}^{-3}$ were observed. In addition, large concentrations of ozone $\left(\mathrm{O}_{3}\right)$ were detected with the maximum value of about $1 \times 10^{21} \mathrm{~m}^{-3}$. The O-atom density was maximal at 0.6 vol. $\%$ of $\mathrm{O}_{2}$ in the noble gas, whereas the $\mathrm{O}_{3}$ density continued to increase with increasing $\mathrm{O}_{2}$ admixture. The concentration of $\mathrm{O}$ atoms decreased with increasing distance from the APPJ nozzle, whereas the opposite behavior was observed for $\mathrm{O}_{3}$.

Sousa et al. used a capacitively coupled radiofrequency plasma jet (RF-APPJ) and the APPJ driven by a $\mathrm{kHz}$ discharge to investigate the formation of singled delta oxygen $\mathrm{O}_{2}$ (a) using infrared optical emission spectroscopy [14]. The carrier gas was $\mathrm{He}$ with various $\mathrm{O}_{2}$ admixtures up to 1 vol.\%. Similar dependencies of the $\mathrm{O}_{2}$ (a) density versus discharge parameters (i.e., $\mathrm{O}_{2}$ admixture, dissipated power) were found for both sources. The absolute density of $\mathrm{O}_{2}(\mathrm{a})$ was of the order of $10^{20} \mathrm{~m}^{-3}$; however, the 
maximum value found was about $6 \times 10^{21} \mathrm{~m}^{-3}$. The substantial concentrations of the $\mathrm{O}_{2}$ (a) molecules were found even several centimeters downstream of the effluent zone.

Systematic research on the generation of $\mathrm{O}$ atoms in the effluent of an APPJ was performed by Reuter et al. [15]. They used an RF-driven discharge sustained either in He or Ar with a small $\mathrm{O}_{2}$ admixture. The O-atom density at the nozzle reached the value of approximately $1 \times 10^{22} \mathrm{~m}^{-3}$ (for $\mathrm{He}+0.5$ vol. $\% \mathrm{O}_{2}$ ). 'A substantial amount of $\mathrm{O}$ atoms persisted even $10 \mathrm{~cm}$ away from the nozzle. Unlike other authors, Reuter et al. used a high-power discharge, because they managed to operate the discharge at the power of $150 \mathrm{~W}$. Interesting enough, the gas temperature remained below $80{ }^{\circ} \mathrm{C}$ even at the nozzle when the He flux was $2 \mathrm{~m}^{3} \cdot \mathrm{h}^{-1}$. Reuter et al. also performed modeling of APPJ sustained in Ar with 1 vol. $\% \mathrm{O}_{2}$ [16]. The O-atom density decreased quite monotonically with the distance from the nozzle. The maximum O-atom density at the nozzle was almost $4 \times 10^{21} \mathrm{~m}^{-3}$, whereas at the distance of $5 \mathrm{~mm}$ it dropped to approximately $1 \times 10^{21} \mathrm{~m}^{-3}$.

Properties of time-modulated RF APPJ in Ar with 1 vol.\% $\mathrm{O}_{2}$ were studied by Jiang et al [17]. The authors found the densities of $\mathrm{O}$ atoms and $\mathrm{O}_{3}$ of the order of $10^{21} \mathrm{~m}^{-3}$. A very high degree of dissociation was observed during each discharge pulse. The signal of $\mathrm{O}$ atoms decreased quickly after the pulse, whereas the $\mathrm{O}_{3}$ molecules persisted over a microsecond after each pulse. The O-atom density decreased gradually with increasing nozzle distance; however, the opposite trend was observed for the $\mathrm{O}_{3}$ density. The presence of a substrate in contact with the plasma jet had an influence on the O-atom density within the jet because of a change in the gas flow pattern causing different air admixing.

Schröter et al. measured the concentration of $\mathrm{OH}$ radicals in the humidified He discharge sustained in an RF-driven APPJ [18]. They found an extensive dissociation of $\mathrm{H}_{2} \mathrm{O}$ molecules upon plasma conditions. The density of $\mathrm{OH}$ radicals was about $3 \times 10^{20} \mathrm{~m}^{-3}$. Such a large density expanded several $\mathrm{cm}$ along the discharge channel. An order of magnitude lower $\mathrm{OH}$ density was observed by Wang et al. [19]. The exact mechanisms of radical kinetics are still not known because of various reactions, including those with metastable Ar atoms [20].

Recently, Golda et al. measured the UV/VUV radiation arising from APPJ sustained in He and $\operatorname{Ar}$ [1]. The gas flow rates were just above $1 \mathrm{slm}$, and a small admixture of $\mathrm{O}_{2}$ or $\mathrm{N}_{2}$ was added. In the case of Ar feed gas, the $\mathrm{Ar}_{2}{ }^{*}$ continuum expanded in the range of wavelengths of roughly between $115-135 \mathrm{~nm}$.

The brief survey of state-of-the-art indicates a rather high degree of dissociation of reactive molecules in plasma sustained in noble gases. Different authors used different configurations, but the concentration of $\mathrm{O}$ atoms was roughly about $10^{21} \mathrm{~m}^{-3}$. Because APPJ is a rich source of locally confined reactive species, it may be very suitable for the localized functionalization of products. An example is a requirement for enhanced printability of polymeric packaging. In such cases, the printable area expands only on a small segment of the product. Several authors have already reported results on the surface finish of the polymers using APPJ [5-9], and few presented surface mapping or line analyses of induced modification versus the discharge parameters $[4,11,12,21]$. Recently, we reported systematic research on the surface finish of the polyethylene terephthalate polymer [10]. We found enhanced wettability of this material at prolonged treatment times. The maximum wettability was observed after about $10 \mathrm{~s}$ of treatment with APPJ sustained in Ar with traces of water vapor. The distance between the nozzle and the substrate was found to be crucial for the desired surface finish. Although the glowing plasma jet expanded up to $3 \mathrm{~cm}$ from the nozzle, the evolution of the surface wettability was observed already for lower distances, whereas, at $4 \mathrm{~cm}$, the effect was marginal even after prolonged treatment times.

In the present paper, we present the results of a comprehensive investigation of the evolution of surface wettability versus distances as well as plasma treatment time for the case of polystyrene. Unlike the prior art, we focused on the time evolution of the spot size of the affected area versus plasma treatment time when the samples were in direct contact with the glowing plasma jet. In another set of experiments, we show the evolution at the edge of the glowing plasma. The evolution of surface wettability and functionalization versus the distance of the sample from the plasma jet is also elaborated. 


\section{Materials and Methods}

Polystyrene (PS) foil with a thickness of $125 \mu \mathrm{m}$ was purchased from Goodfellow Ltd. (Huntingdon, UK). This aromatic polymer contains carbon and hydrogen only with a chemical formula $\left(\mathrm{C}_{8} \mathrm{H}_{8}\right)_{\mathrm{n}}$. Polymer samples were cut to dimensions of $5 \times 5 \mathrm{~cm}^{2}$ and mounted on to a wooden plate away from any metallic object, so they were at a floating potential upon treatment with gaseous plasma. A single-electrode plasma jet (home-made) was sustained using a frequency of $25 \mathrm{kHz}$ and a peak-to-peak voltage of $7 \mathrm{kV}$. Ar gas was leaked at a flow rate of $1 \mathrm{slm}$ through a dielectric tube (made from quartz glass) with an inner diameter of $3 \mathrm{~mm}$. The home-made plasma device was installed in a laboratory where the ambient air temperature was $24{ }^{\circ} \mathrm{C}$, and the relative humidity was $65 \%$. The tube was exposed to ambient conditions before performing plasma experiments; therefore, some water molecules that desorb from a dielectric tube can be present in the feed gas. Gaseous plasma was characterized by optical emission spectroscopy. We used AvaSpec-3648 Fiber Optic Spectrometer (Avantes, Apeldoorn, The Netherlands). The spectrometer was connected to the collimation lenses via an optical fiber, as shown in Figure 1. Optical spectra were acquired $5 \mathrm{~mm}$ from the nozzle of the APPJ. The schematic of the experimental set-up is shown in Figure 1.

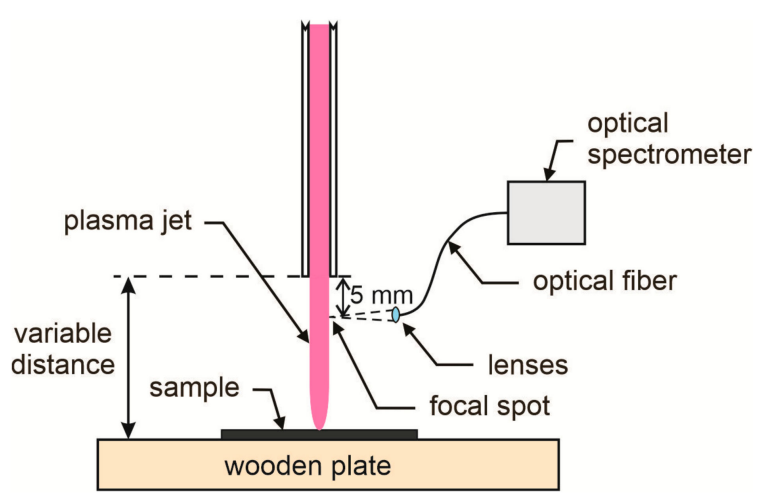

Figure 1. Schematic of the experimental set-up (not to scale).

The samples were treated with the APPJ at various distances from the nozzle ranging from 2 to $45 \mathrm{~mm}$ and at various treatment times between $0.5 \mathrm{~s}$ and $10 \mathrm{~min}$. After treatment, the samples were probed for wettability with an instrument DSA100 from Kruss GmbH (Hamburg, Germany). The device enabled the automatic deposition of water droplets over the almost arbitrary surface area. For this study, we deposited 73 droplets with a volume of $1 \mu \mathrm{L}$ on the surface of the samples and acquired the apparent water contact angle (WCA) simultaneously. An apparent water contact angle was measured using a sessile drop method. The droplets were deposited every $5 \mathrm{~mm}$ in such a way that the whole surface was mapped. More details about measurements and experimental setup can be found in our previous paper [10].

Some samples were also characterized by X-ray photoelectron spectroscopy (XPS) to investigate chemical modifications. XPS characterization was performed using TFA-XPS spectrometer (Physical Electronics, Münich, Germany). The samples were irradiated with monochromatic $\mathrm{Al} \mathrm{K} \alpha_{1,2}$ radiation at $1486.6 \mathrm{eV}$. The diameter of the analyzed area was approximately $400 \mu \mathrm{m}$. Spectra were acquired at an electron take-off angle of $45^{\circ}$ in the center of the treated samples. XPS-survey spectra were acquired at a pass-energy of $187 \mathrm{eV}$ using an energy step of $0.4 \mathrm{eV}$, whereas high-resolution C1s spectra were measured at a pass-energy of $23.5 \mathrm{eV}$ using an energy step of $0.1 \mathrm{eV}$. An additional electron gun was used to avoid charging of the samples. Spectra were calibrated by setting the C-C peak to $284.8 \mathrm{eV}$. The MultiPak v8.1c software (v8.1c (2006), Ulvac-Phi Inc., Physical Electronics, Kanagawa, Japan) was used to analyze the spectra. Linear background subtraction was used. The following subpeaks were found in carbon C1s spectra: C-C peak at $284.8 \mathrm{eV}, \mathrm{C}-\mathrm{O}$ peak at $286.2 \mathrm{eV}, \mathrm{C}=\mathrm{O}$ and $\mathrm{O}-\mathrm{C}-\mathrm{O}$ peaks at $287,5 \mathrm{eV}, \mathrm{O}-\mathrm{C}=\mathrm{O}$ peak at $288.6 \mathrm{eV}$ as well as $\mathrm{O}-\mathrm{C}(=\mathrm{O})-\mathrm{O}$ peak at $289.7 \mathrm{eV}$, and the aromatic shake-up peak $\pi-\pi^{*}$ at $291.5 \mathrm{eV}$. 


\section{Results and Discussion}

\subsection{Plasma Characterization}

Plasma was briefly characterized by optical emission spectroscopy. A typical spectrum is shown in Figure 2. The transitions between highly excited Ar atoms are observed in the red part of the spectrum. These transitions are among the levels of highly excited Ar atoms. Any transition to the ground state occurs at much lower wavelengths (i.e., in VUV range) and could not be probed by our optical spectrometer. According to Golda et al., the major radiation in the VUV range of Ar plasma occurs from the $\mathrm{Ar}_{2}{ }^{*}$ continuum [1]. The spectrum in Figure 2 also shows a rather intensive $\mathrm{OH}$ band with the bandhead at approximately $309 \mathrm{~nm}$. Although water vapor is just an impurity, so the concentration of $\mathrm{OH}$ radicals is much lower than the concentration of Ar, the radiation is intensive because of the high excitation probability and good dissociation of water vapor in the discharge. It was reported that the presence of water vapor in Ar plasma suppresses the $\mathrm{Ar}_{2}{ }^{*}$ continuum $[1,22,23]$. The addition of such molecular species causes a change in the efficiency of the energy transfer between electrons and heavy particles like water molecules what causes a reduction of electron temperature [22]. Still, radiation in the VUV range of Ar plasma jet is significant [1]. However, the presence of water vapor does not affect only Ar lines. As reported by Nikiforov et al. [22], water vapor will also affect the intensity of oxygen lines much more strongly than Ar lines, because more energy is needed to produce $\mathrm{O}$ atoms from $\mathrm{H}_{2} \mathrm{O}$ than to excite Ar. Such weak oxygen lines were also observed by other authors [22-24]. As reported by Park et al. [24], oxygen peaks in Ar plasma are very weak even when $\mathrm{O}_{2}$ is added to Ar, although $\mathrm{Ar} / \mathrm{O}_{2}$ plasma is a known source of reactive oxygen species. In our case, a very weak $\mathrm{O}$ line at $777 \mathrm{~nm}$ was observed only at the shortest distance of $2 \mathrm{~mm}$ from the APPJ nozzle, whereas at the distance of $5 \mathrm{~mm}$ or more, it was no longer noticeable. Spectrum in Figure 2 also shows weak excited $\mathrm{N}_{2}$ lines. As also mentioned by Park et al. weak $\mathrm{N}_{2}$ lines can be explained by a lack of exciting agents because ionization and the charge transfer to $\mathrm{N}_{2}{ }^{+}$are suppressed in the Ar plasma [24]. Nevertheless, we can conclude that our APPJ is a source of oxidizing species and VUV photons useful for surface functionalization and thus for increasing the wettability of a polymer sample.

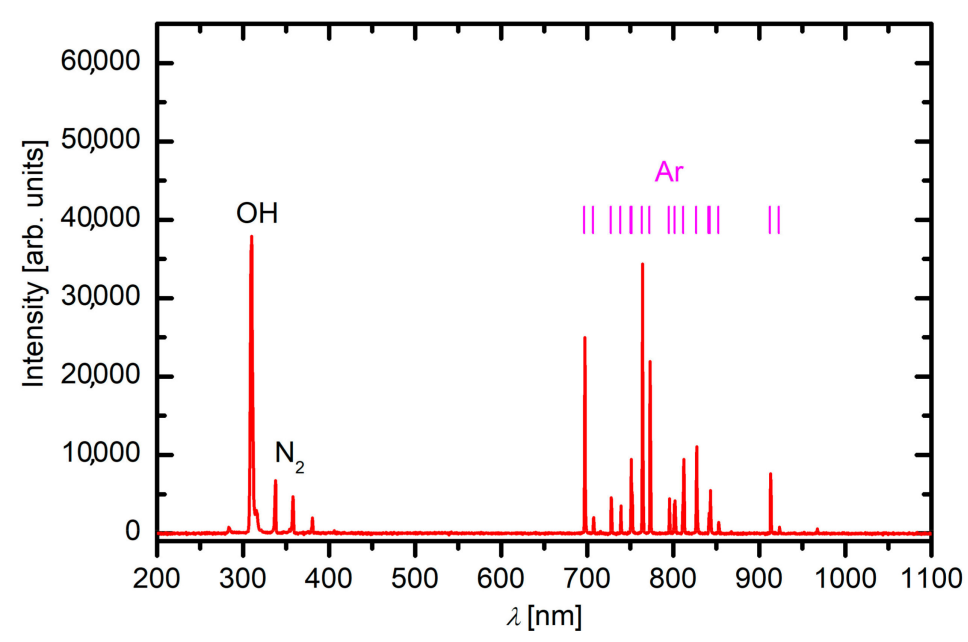

Figure 2. Optical emission spectrum measured at a distance of $5 \mathrm{~mm}$ from the nozzle.

\subsection{The Effect of the Sample-to-Nozzle Distance}

The 2D/3D mapping of the surface wettability was performed for various treatment conditions. Figure 3 shows the dependence of the surface wettability versus the distance between the nozzle and the sample. A rather large treatment time of $30 \mathrm{~s}$ was chosen to make any surface modification visible also for rather large distances between the nozzle and the sample. 

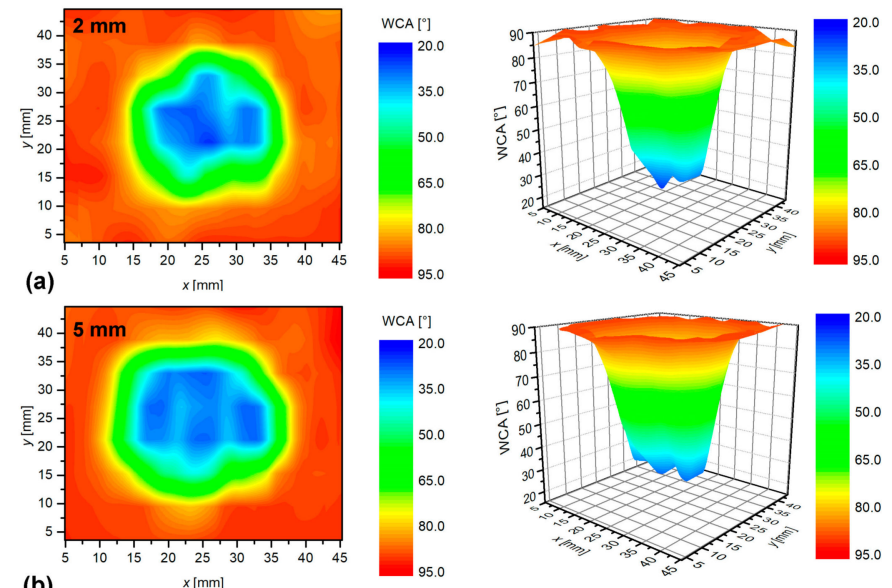

(b)

$x[\mathrm{~mm}]$
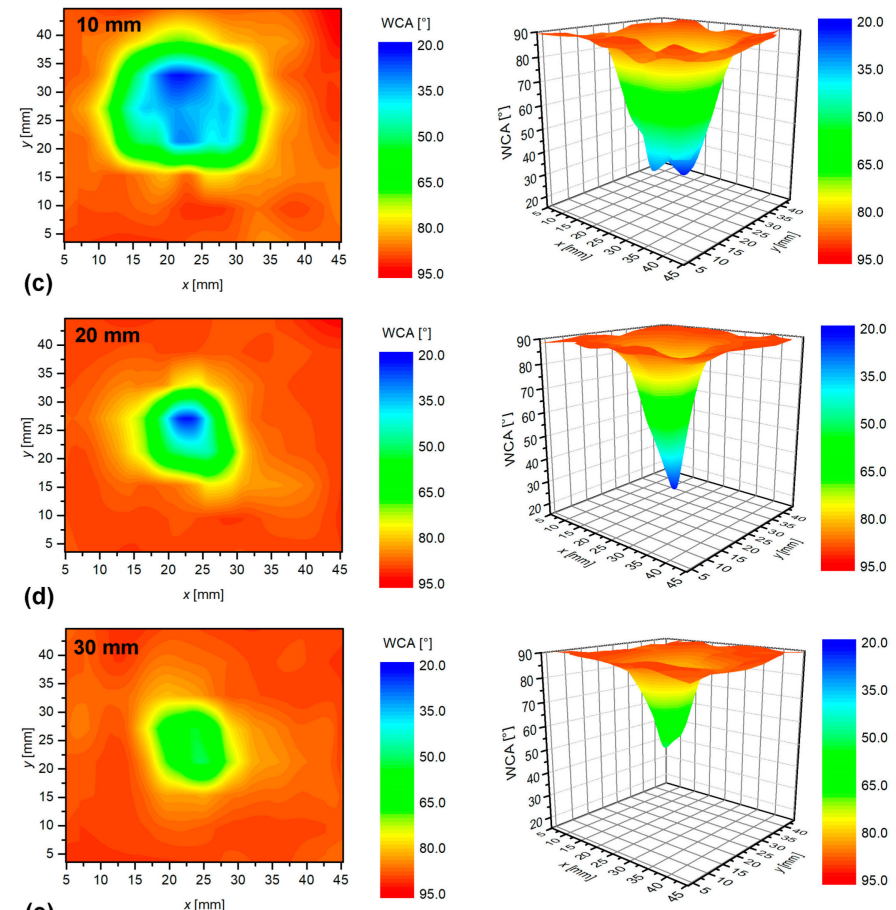

(e)
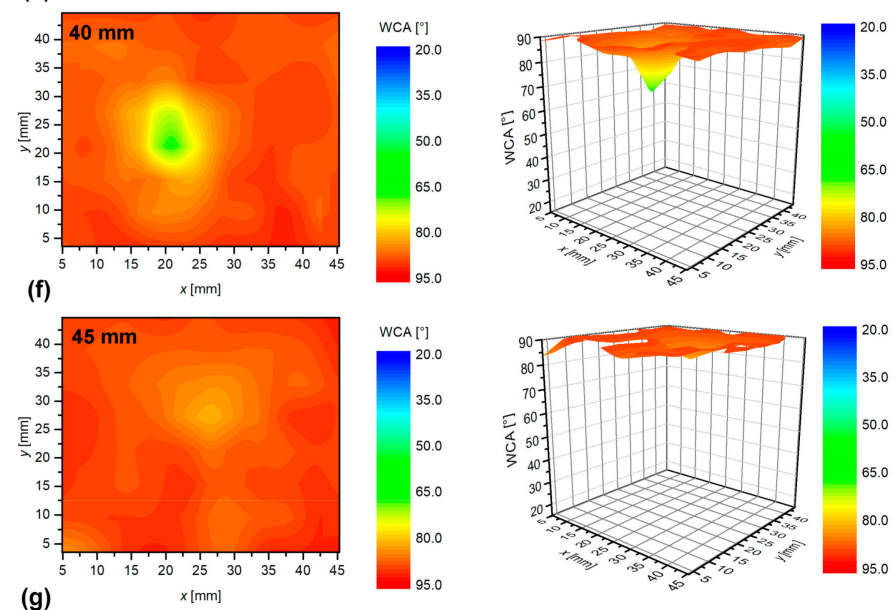

Figure 3. Evolution of the surface wettability for polystyrene treated at various distances from the atmospheric-pressure plasma jets (APPJ) nozzle: (a) $2 \mathrm{~mm}$, (b) $5 \mathrm{~mm},(\mathbf{c}) 10 \mathrm{~mm}$, (d) $20 \mathrm{~mm},(\mathbf{e}) 30 \mathrm{~mm}$, (f) $40 \mathrm{~mm},(\mathrm{~g}) 45 \mathrm{~mm}$. The treatment time was $30 \mathrm{~s}$. 
The length of the visible plasma jet was $30 \mathrm{~mm}$. One can observe rather equal effects for distances between 2 and $10 \mathrm{~mm}$ (Figure $3 \mathrm{a}-\mathrm{c}$ ). The minimal achievable WCA is about $20^{\circ}$, which is consistent with results reported by other authors. Bradley et al. reported values of approximately $25^{\circ}$ for polystyrene treated with a He jet aligned parallel with the surface [25]. Also Dowling et al. reported values between $20-30^{\circ}$ using a direct-current pulsed APPJ feed with dry-compressed air [26]. Interestingly, Fricke et al. found values as low as $5^{\circ}$ for polystyrene treated with $1.7 \mathrm{MHz}$ APPJ in $\mathrm{Ar} / \mathrm{O}_{2}$ gas [27]. One possible explanation for obtaining such superhydrophilic surface is the addition of $\mathrm{O}_{2}$ and thus a higher concentration of reactive oxygen species that caused better surface functionalization [9].

At a distance of $20 \mathrm{~mm}$, however, the hydrophilicity is much less pronounced than at shorter distances. Not only the spot size is much smaller than at shorter distances, but also the optimal wettability is focused to a small spot inside the affected area, as shown in Figure 3d. This effect is even more pronounced with further increasing of the distance between the sample and the nozzle. Figure 3e shows a further shrinkage of the spot size as well as a rather poor wettability even in the center. As mentioned earlier, the distance of $30 \mathrm{~mm}$ corresponds to the edge of the glowing plasma. The rapid decrease of the surface wettability is explained by axial gradients of reactive oxygen species. As reported in the introduction, various authors have shown that the O-atom density decreases at least linearly if not more with the distance from the nozzle $[13,15,17]$. However, for the $\mathrm{O}_{3}$ molecules, which are also capable of increasing the wettability of polymers, they found the opposite variation with a distance. Large concentrations of $\mathrm{O}_{3}$ were found even far away from the nozzle. The $\mathrm{O}_{3}$ molecules definitely form upon the interaction of $\mathrm{O}$ atoms with $\mathrm{O}_{2}$ molecules, but in our case, no oxygen was added to the discharge zone, so the formation of essential amounts of such rather long-living reactive species is unlikely to occur. The rapid decrease of the surface wettability with increasing distance is therefore explained by a lack of relatively long-living reactive oxygen species capable of functionalization of polystyrene. The effect is even more pronounced at a distance of $40 \mathrm{~mm}$ (Figure 3f). Here, the activated area shrinks to the diameter of a few mm only. At a distance of $45 \mathrm{~mm}$, the activation of the polymer is at the edge of the experimental error. Such a rapid decrease also indicates the marginal effect of any UV radiation on the surface finish, as shown by Nishime et al. [12]. They found that UV radiation is decreasing with increasing distance between the plasma jet and the sample. This is even more pronounced for VUV radiation, which has a very limited penetration depth in the surrounding atmosphere in comparison to UV, so it remains much more focused than UV radiation, and at longer distances, it becomes negligible. By considering these effects, we can conclude that the evolution of the wettability versus the distance indicates that the surface is modified by short-living chemical reactive species such as $\mathrm{OH}$ radicals.

The images in Figure 4 indicate the surface distribution of apparent water contact angles. The minimum water contact angle is defined as the lowest contact angle of any of the water droplets deposited on the samples' surface treated at selected conditions. The minimum WCA versus the distance from the sample is shown in Figure 4. One can observe a small increase of the WCA along with the plasma jet until the edge of the visible plasma (about $30 \mathrm{~mm}$ ). Thereafter, the WCA increases rapidly with increasing distance. The wettability obtained in the center of the affected zone, therefore, does not depend much on the distance as long as the sample is in contact with the glowing plasma, and the treatment time is rather long (surface saturation).

Figure 5 shows the evolution of the diameter of the spot size of the modified area versus the distance between the nozzle and the sample. The results are slightly scattered because it was rather difficult to determine the edge of the affected zone. A yellow ring in Figure 3 was chosen as a border of the affected zone. Nevertheless, the diameter of the spot size decreases with increasing distance. The spot size is always larger than the diameter of the discharge tube, indicating the radial spreading of the reactive gaseous species. 


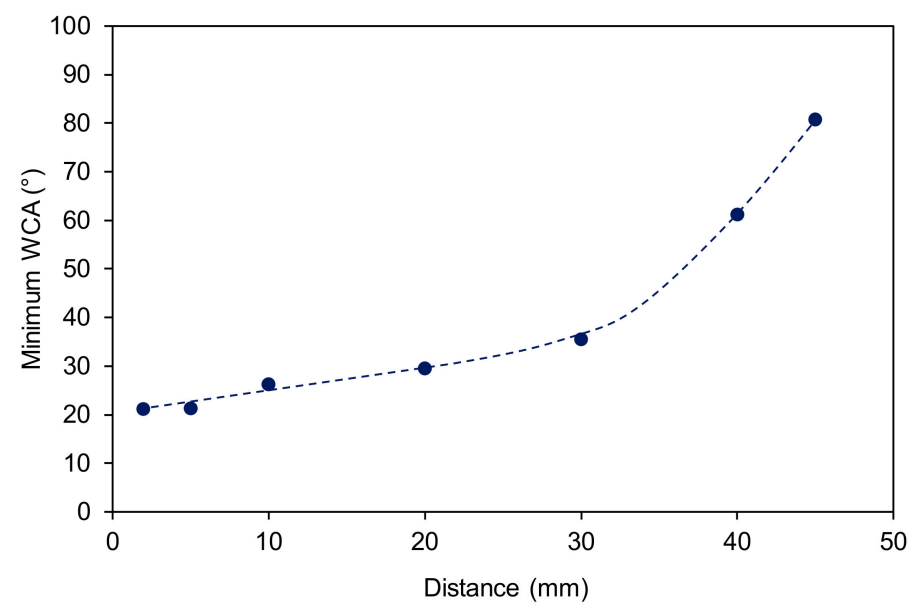

Figure 4. The minimum apparent water contact angle of polystyrene samples treated for $30 \mathrm{~s}$ versus the distance.

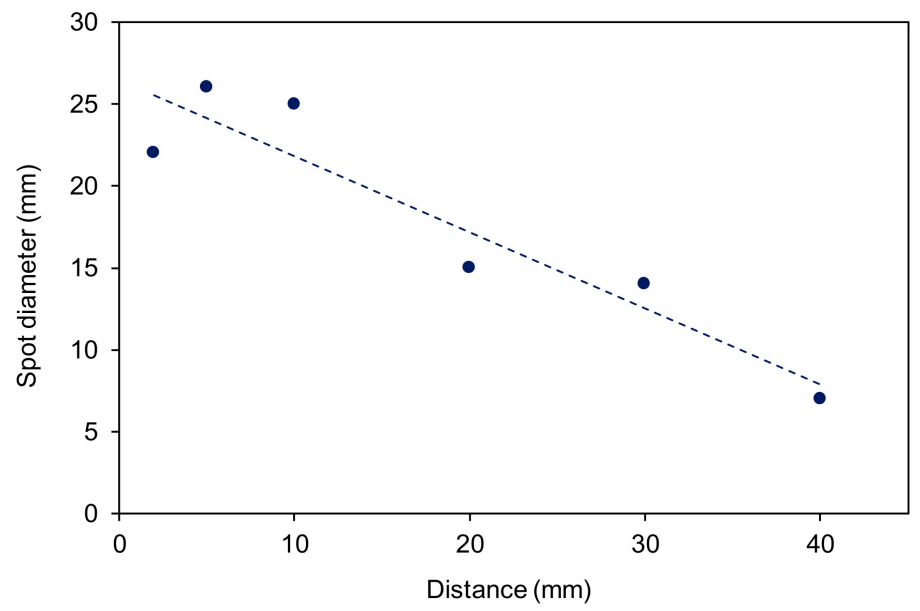

Figure 5. The diameter of the treated zone versus the distance as estimated from Figure 3.

The samples treated for $30 \mathrm{~s}$ at various distances were also characterized by XPS. Because this technique is time-consuming, we performed characterization only in the center of the affected area. The XPS surface composition is shown in Figure 6. One can see a rather constant concentration of oxygen for distances when the sample was in contact with the glowing plasma, i.e., up to $30 \mathrm{~mm}$. The oxygen concentration is approximately 20 at. $\%$, and minute concentrations of nitrogen were found as well. The appearance of nitrogen within the surface film of polystyrene can be explained by the presence of reactive nitrogen species in the plasma jet because Figure 2 shows some radiation from nitrogen.

High-resolution XPS spectra of carbon were also measured for all distances and are shown in Figure 7. Several functional groups typical for plasma-treated polystyrene can be identified, including the highly-polar carboxyl and carbonate groups $[9,28,29]$. One can observe only a gradual decrease of their intensity (in the range between 286 and $290 \mathrm{eV}$ ) for distances between 2 and $30 \mathrm{~mm}$ that are corresponding to the visible part of the jet, followed by a more significant decrease for the polystyrene treated at a distance of $40 \mathrm{~mm}$.

There is a fair correlation between the XPS results and the WCA measurements. Figure 8 represents the behavior of the minimum WCA and the $\mathrm{O} / \mathrm{C}$ ratio versus the distance between the nozzle and the sample. A significant change in both curves appears at the end of the glowing plasma jet, i.e., $30 \mathrm{~mm}$. The chemistry of the afterglow is, therefore, much different from the reactions in the glowing plasma. 
A feasible explanation of this effect is the short lifetime of species available in our configuration, i.e., predominantly $\mathrm{OH}$ radicals and possibly $\mathrm{O}$ atoms.

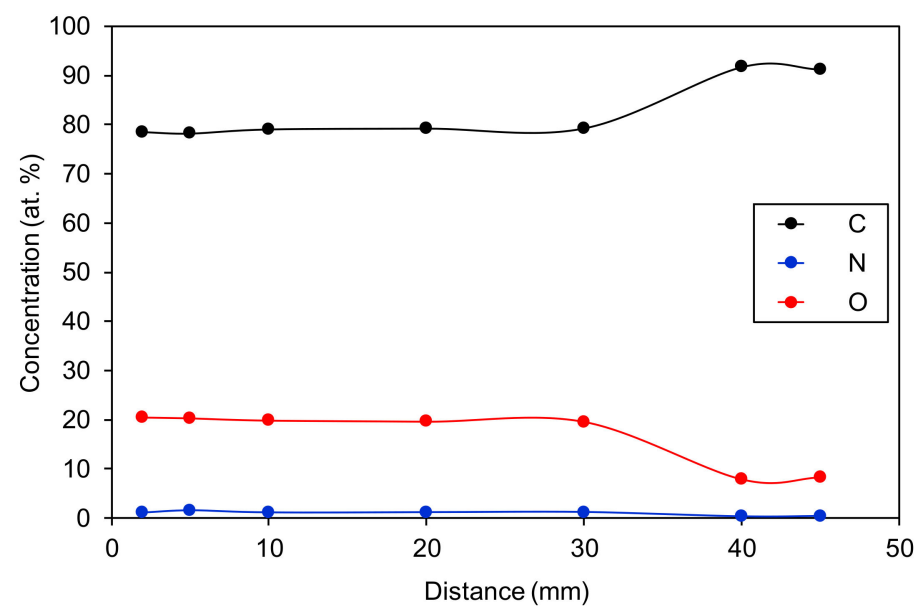

Figure 6. The surface composition of polystyrene measured in the center of the treated zone versus a distance of the APPJ nozzle from the sample surface. The treatment time was $30 \mathrm{~s}$.

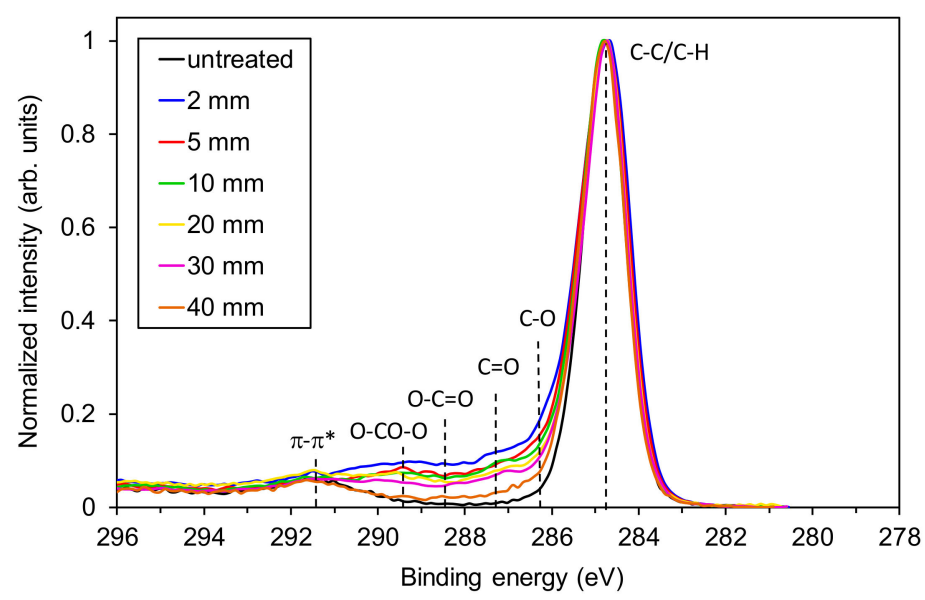

Figure 7. X-ray photoelectron spectroscopy (XPS) C1s spectra of polystyrene samples measured in the center of the treated zone versus a distance of the APPJ nozzle from the sample surface. The treatment time was $30 \mathrm{~s}$.

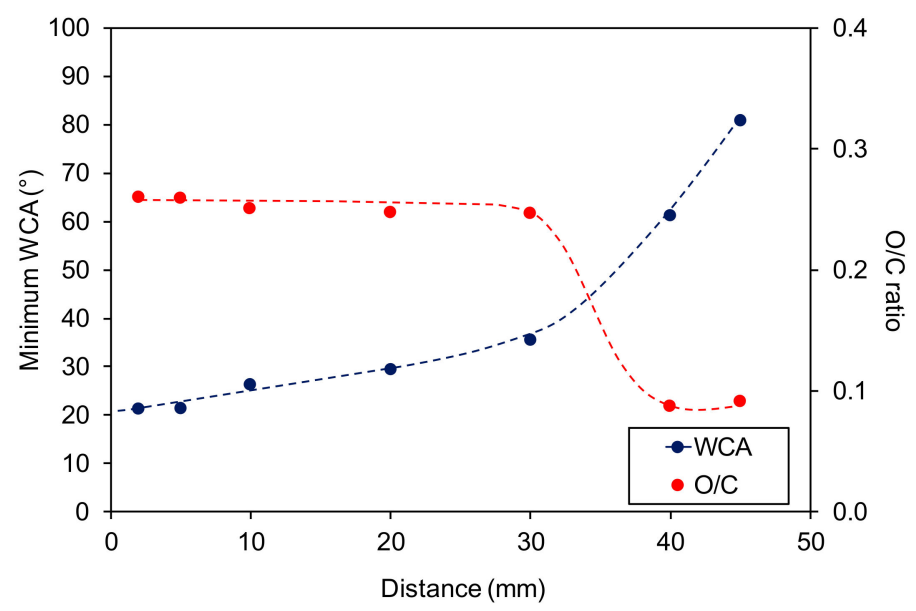

Figure 8. The correlation between the minimum apparent water contact angle and $\mathrm{O} / \mathrm{C}$ ratio. 


\subsection{Effect of Treatment Time}

The temporal evolution of the surface wettability is shown in Figures 9 and 10. Figure 9 was obtained by measuring the 2D distribution of the apparent water contact angle on samples placed 5 $\mathrm{mm}$ below the nozzle. Figure $9 \mathrm{a}$ reveals a rather good functionalization in the center of the affected area even after half a second of plasma treatment. Such a rapid functionalization is a consequence of a reasonable amount of reactive oxygen species in the glowing plasma, as well as the high affinity of polystyrene for reaction with reactive oxygen species. Previous experiments performed in the low-pressure oxygen afterglows indicated that the O-atom fluence as low as $10^{21} \mathrm{~m}^{-2}$ was enough to functionalize polystyrene surface [28]. As shown in the introduction, the density of either oxygen atoms or $\mathrm{OH}$ radicals in the APPJ sustained in noble gases easily exceeds $10^{20} \mathrm{~m}^{-2}$. Such a density of reactive species will result in the flux over $10^{22} \mathrm{~m}^{-2} \cdot \mathrm{s}^{-1}$. The fluence of $10^{21} \mathrm{~m}^{-2}$ will then be achieved in approximately $0.1 \mathrm{~s}$. The rapid functionalization, as observed in Figure $9 \mathrm{a}$, therefore, indicates an excellent affinity of polystyrene to reactive oxygen species. Here, it is worth mentioning that not all polymers exhibit such properties. E.g., the polyethylene terephthalate polymer was well-activated in the center of the affected zone only after a few seconds of treatment with the same APPJ [10].

Prolonging treatment to $5 \mathrm{~mm}$ has a little effect on the maximum wettability in the center of the affected zone. In Figure $9 \mathrm{~b}-\mathrm{i}$, it is clearly shown that the minimal WCA of just above $20^{\circ}$ is achieved already upon the shortest treatment time. The changes are observed only in the size of the surface area, revealing the spreading of improved wettability. The area increases monotonously with the increasing treatment time. Finally, after $600 \mathrm{~s}$, almost the entire surface area of $5 \times 5 \mathrm{~cm}^{2}$ becomes wettable. The effect can be explained by minute concentrations of reactive oxygen species far away from the jet axis, whereas the effect of radiation can be excluded. According to Golda et al., VUV cannot propagate through the ambient air because of strong absorption [1]; therefore, their effect on surface modification away from the axis has to be excluded. This is also in agreement with Nishime et al. [12], who showed that VUV radiation is laterally very limited. This is further supported by our previous paper, where we have used the $\mathrm{MgF}_{2}$ optical window to treat the polyethylene terephthalate only with VUV photons, whereas reactive oxygen species were eliminated. The diameter of the area treated with VUV was roughly $10 \mathrm{~mm}$, and it was approximately three-times smaller than without the $\mathrm{MgF}_{2}$ window. The spreading of the surface area is, therefore, likely to be a consequence of a small but finite concentration of reactive oxygen species even a few centimeters away from the discharge axis.

More interesting are the results shown in Figure 10. In this case, polystyrene samples were placed at the end of the glowing plasma jet, i.e., $30 \mathrm{~mm}$ from the nozzle. Interestingly enough and opposite to Figure $9 \mathrm{~b}$, the WCA remains unchanged even after a second of plasma treatment, as revealed from Figure 10a. A few seconds of plasma treatment causes the development of an affected area, but the area is much smaller than at any experiment performed for the sample position at $5 \mathrm{~mm}$ from the nozzle. In fact, the diameter of the spot in Figure $10 \mathrm{~b}-\mathrm{d}$ is not much larger than the diameter of the discharge tube. At such a large distance, the concentration of reactive oxygen species is much lower than at $5 \mathrm{~mm}$, and also, their radial spreading is reduced. There should be strong axial gradients of the reactive oxygen species density in the APPJ used in this study. As reported by Ellerweg et al. [13], Reuter et al. [16] or Jiang et al. [17], the density of short-living radicals like $\mathrm{O}$ atoms decreased with increasing distance from the nozzle. According to Reuter et al. [16], the decrease was rather linear, and the O-atom density dropped for an order of magnitude at a distance of approximately $1 \mathrm{~cm}$. By considering these data, one should observe highly wettable surfaces for treatment times one or two orders of magnitude longer than at $5 \mathrm{~mm}$. In fact, Figure $10 \mathrm{~g}$ indicates that the wettability shows a WCA pattern similar to the one in Figure 9a. The treatment time for Figure $10 \mathrm{~g}$ was 100 times larger than for Figure 9a. The observations summarized in Figures 9 and 10, therefore, confirm strong axial gradients of plasma radical in our APPJ. 

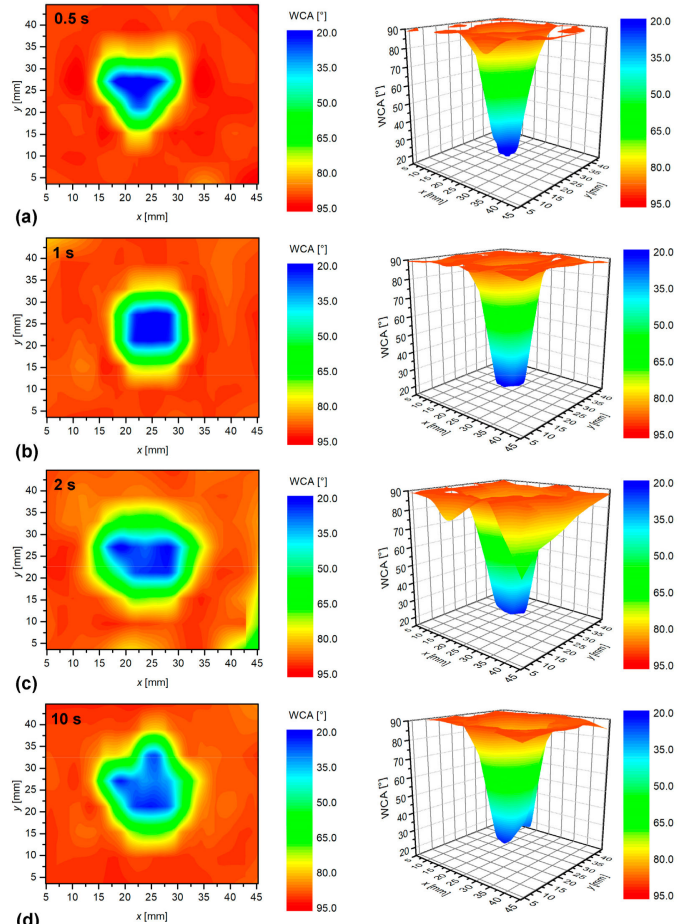

(d)
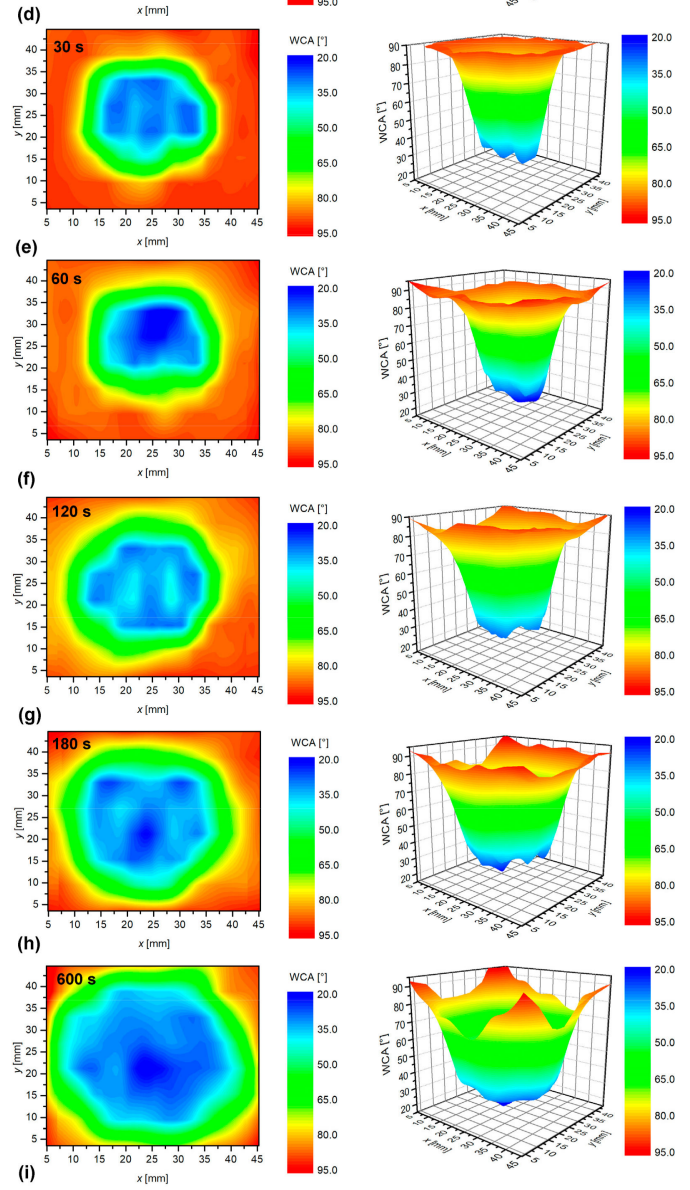

Figure 9. Evolution of the surface wettability for polystyrene treated at various treatment times for the sample distances of $5 \mathrm{~mm}$ from the APPJ nozzle: (a) $0.5 \mathrm{~s}$, (b) $1 \mathrm{~s}$, (c) $2 \mathrm{~s}$, (d) $10 \mathrm{~s}$, (e) $30 \mathrm{~s}$, (f) $60 \mathrm{~s}$, (g) 120 $\mathrm{s}$, (h) $180 \mathrm{~s},(\mathbf{i}) 600 \mathrm{~s}$. 

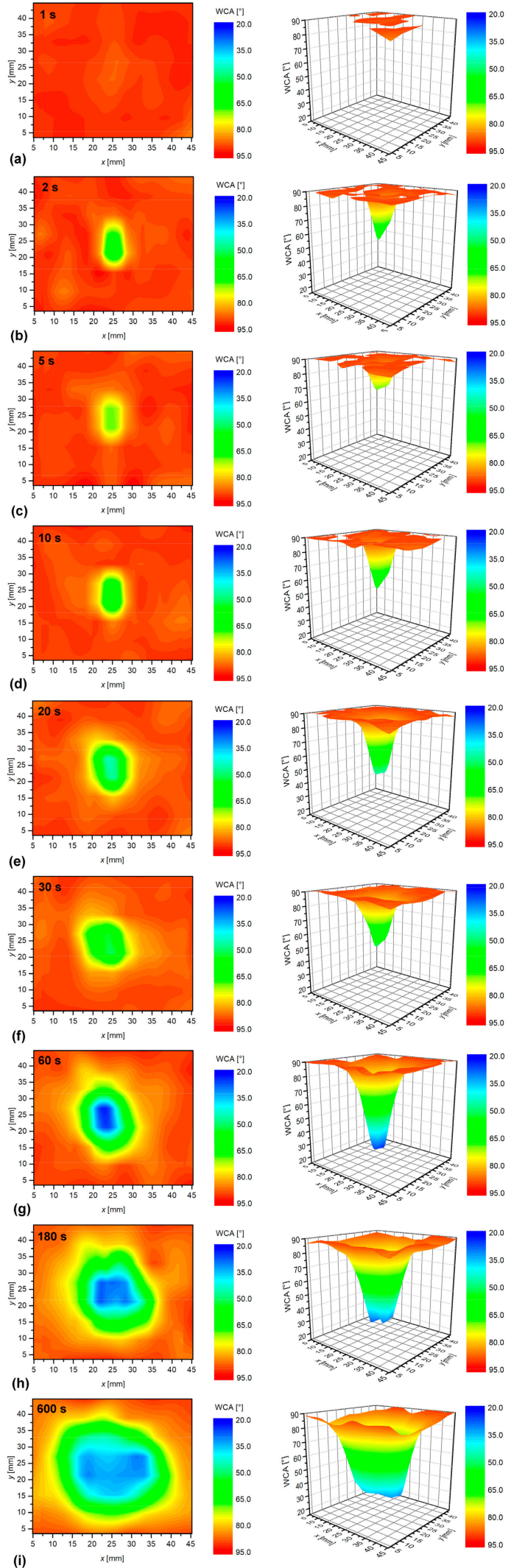

Figure 10. Evolution of the surface wettability for polystyrene treated at various treatment times for the sample distances of $30 \mathrm{~mm}$ from the APPJ nozzle: (a) $1 \mathrm{~s}$, (b) $2 \mathrm{~s}$, (c) $5 \mathrm{~s}$, (d) $10 \mathrm{~s}$, (e) $20 \mathrm{~s}$, (f) $30 \mathrm{~s}$, (g) $60 \mathrm{~s}$, (h) $180 \mathrm{~s}$, (i) $600 \mathrm{~s}$. 
The minimal WCA in the affected area versus treatment time for both distances is shown in Figure 11. As already observed in Figures 9 and 10, the wettability saturates, and the WCA does not decrease any more after saturation. Saturation is faster for almost two orders of magnitude for the samples treated at a distance of $5 \mathrm{~mm}$. For low-pressure plasmas, it was reported that prolonged plasma treatment may sometimes cause WCA to increase again, which is a consequence of overtreatment that can cause degradation of functional groups and thus loss of enhanced wettability [30]. Highly oxidized functional groups are not stable but tend to decay spontaneously. The decay is much faster at elevated temperatures than at room temperature. As shown in Figure 11, this is not observed in our case. The fact that the minimal WCA does not increase even after $10 \mathrm{~min}$ of treatment at the shortest distance indicates a real cold gaseous plasma. As explained already in the introduction, the kinetic temperature of plasma sustained in noble gases remained close to the room temperature because of the lack of superelastic collisions.

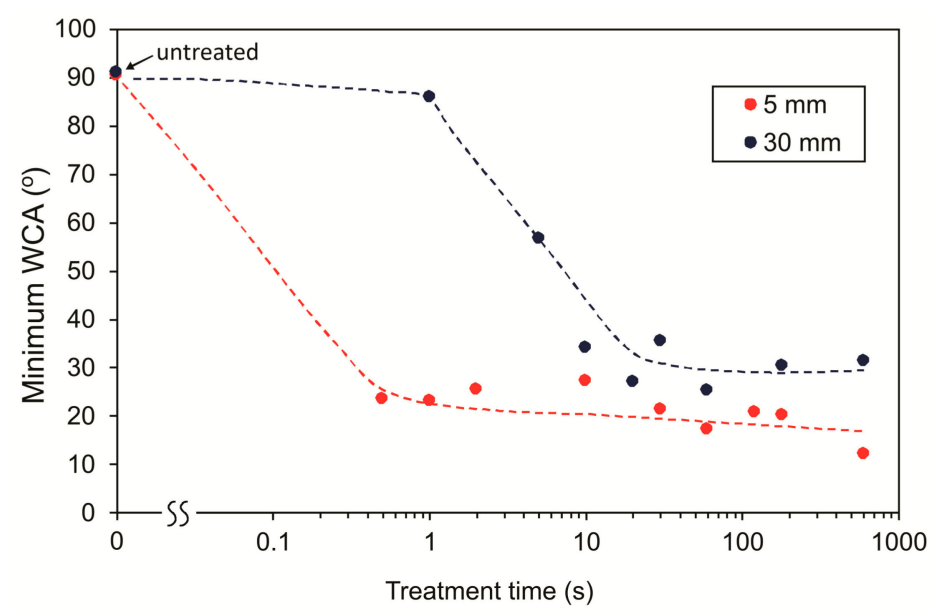

Figure 11. The minimum apparent water contact angle of polystyrene samples exposed to APPJ at distances of 5 and $30 \mathrm{~mm}$ versus treatment time.

Figure 12 represents the diameter of the hydrophilic area versus the treatment time, as estimated from Figures 9 and 10. The diameter is much larger for the samples positioned close to the nozzle, which is explained by the much larger density of reactive species as compared to the edge of the glowing plasma.

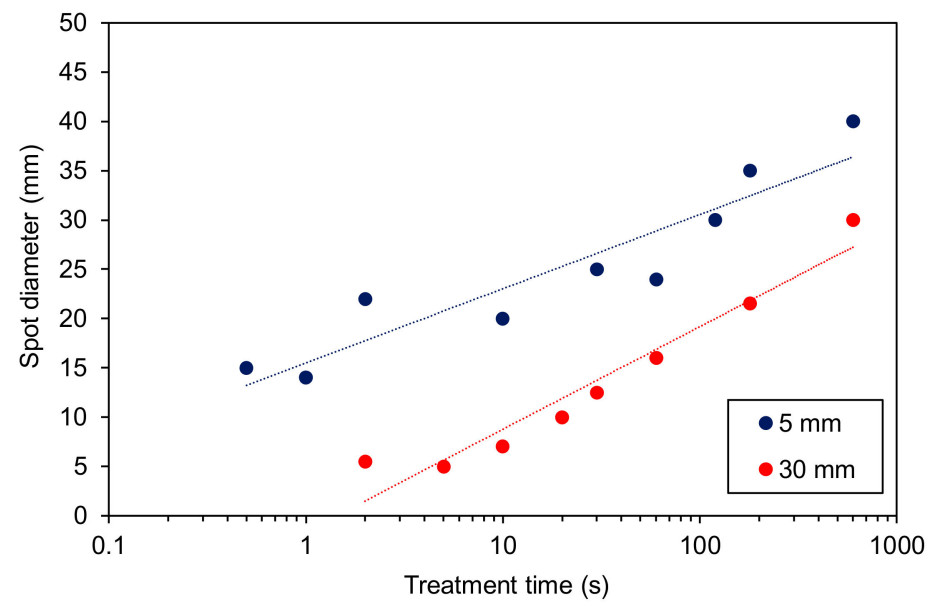

Figure 12. The diameter of the plasma-treated zone on polystyrene samples versus treatment time as estimated from Figures 9 and 10. 


\section{Conclusions}

The evolution of the surface wettability was investigated systematically at various treatment times and distances between the APPJ nozzle and the polystyrene samples. Although no additional reactive gas was leaked into the plasma jet, and only water vapor represented a source of reactive oxygen species, a rather fast functionalization of the polymer surface was observed. Very fast saturation of wettability of polystyrene on the affected area occurred already after $0.5 \mathrm{~s}$ of APPJ treatment at the shortest distance of $5 \mathrm{~mm}$. By increasing the distance from the nozzle, the wettability progressed much slower. At a distance of $30 \mathrm{~mm}$, which corresponded to the edge of the glowing plasma, the saturation of wettability was observed for about $100 \times$ larger treatment times. The observation is consistent with the gradients of the reactive oxygen species along the axis of the discharge. According to results obtained by other authors, which were presented in the introduction, the density of $\mathrm{OH}$ radicals and $\mathrm{O}$ atoms decreases sharply along the axis, and only relatively long-living species such as $\mathrm{O}_{3}$ are found in the flowing afterglow. In the case of Ar plasma with an admixture of water vapor, the long-living species are almost absent; therefore, the improved wettability of polystyrene at a large distance was observed only upon very long treatment times. The diameter of the affected spot increased rather logarithmically with increasing the treatment time in the range of investigated times. However, when increasing the distance, a linear decrease of the affected spot size was observed. The results of wettability tests performed by measuring the apparent water droplet contact angle are in agreement with the results of functionalization performed by XPS. As the minimum contact angle decreased, the $\mathrm{O} / \mathrm{C}$ ratio increased. The high-resolution XPS C1s spectra indicates formation of higher concentrations of highly-oxidized carbon groups at lower distances. The initial stage of functionalization, however, cannot be revealed from the results presented in this paper and remains a scientific challenge.

The results summarized in this paper therefore indicate that APPJ can be used for localized treatment of samples; however, the effect of treatment depends on the fluence of reactive species to the surface. Higher doses of reactive species obtained at longer treatment times or lower distances cause not just a better wettability but also larger size of the modified area. Therefore, obtaining very small areas of a high wettability still remains a challenge.

Author Contributions: Methodology, G.P.; validation, G.P. and A.V.; formal analysis, G.P. and A.V.; investigation, A.V.; data curation, G.P. and A.V.; writing-original draft preparation, A.V.; writing-review and editing, A.V.; supervision, A.V.; project administration, A.V. All authors have read and agreed to the published version of the manuscript.

Funding: This research was funded by the Slovenian Research Agency, grant number J2-1728 (Initial stages in surface functionalization of polymers by plasma radicals) and P2-0082 (Thin film structures and plasma surface engineering).

Conflicts of Interest: The authors declare no conflict of interest. The funders had no role in the design of the study; in the collection, analyses, or interpretation of data; in the writing of the manuscript, or in the decision to publish the results.

\section{References}

1. Golda, J.; Biskup, B.; Layes, V.; Winzer, T.; Benedikt, J. Vacuum ultraviolet spectroscopy of cold atmospheric pressure plasma jets. Plasma Process. Polym. 2020. [CrossRef]

2. Schulz-von der Gathen, V.; Buck, V.; Gans, T.; Knake, N.; Niemi, K.; Reuter, S.; Schaper, L.; Winter, J. Optical diagnostics of micro discharge jets. Contrib. Plasma Phys. 2007, 47, 510-519. [CrossRef]

3. Guo, H.; Liu, J.; Yang, B.; Chen, X.; Yang, C. Localized etching of polymer films using an atmospheric pressure air microplasma jet. J. Micromech. Microeng. 2014, 25, 015010. [CrossRef]

4. Szili, E.J.; Al-Bataineh, S.A.; Bryant, P.M.; Short, R.D.; Bradley, J.W.; Steele, D.A. Controlling the spatial distribution of polymer surface treatment using atmospheric-pressure microplasma jets. Plasma Process. Polym. 2011, 8, 38-50. [CrossRef]

5. Kehrer, M.; Duchoslav, J.; Hinterreiter, A.; Mehic, A.; Stehrer, T.; Stifter, D. Surface functionalization of polypropylene using a cold atmospheric pressure plasma jet with gas water mixtures. Surf. Coat. Technol. 2020, 384, 125170. [CrossRef] 
6. Luan, P.; Knoll, A.J.; Bruggeman, P.J.; Oehrlein, G.S. Plasma-surface interaction at atmospheric pressure: A case study of polystyrene etching and surface modification by $\mathrm{Ar} / \mathrm{O}_{2}$ plasma jet. J. Vac. Sci. Technol. A 2017, 35, 05C315. [CrossRef]

7. Luan, P.; Kondeti, V.S.S.K.; Knoll, A.J.; Bruggeman, P.J.; Oehrlein, G.S. Effect of water vapor on plasma processing at atmospheric pressure: Polymer etching and surface modification by an $\mathrm{Ar} / \mathrm{H}_{2} \mathrm{O}$ plasma jet. $J$. Vac. Sci. Technol. A 2019, 37, 031305. [CrossRef]

8. Kostov, K.G.; Nishime, T.M.C.; Castro, A.H.R.; Toth, A.; Hein, L.R.O. Surface modification of polymeric materials by cold atmospheric plasma jet. Appl. Surf. Sci. 2014, 314, 367-375. [CrossRef]

9. Bartis, E.A.; Luan, P.; Knoll, A.J.; Hart, C.; Seog, J.; Oehrlein, G.S. Polystyrene as a model system to probe the impact of ambient gas chemistry on polymer surface modifications using remote atmospheric pressure plasma under well-controlled conditions. Biointerphases 2015, 10, 029512. [CrossRef] [PubMed]

10. Vesel, A.; Zaplotnik, R.; Primc, G.; Mozetič, M. Evolution of the surface wettability of PET polymer upon treatment with an atmospheric-pressure plasma jet. Polymers 2020, 12, 87. [CrossRef] [PubMed]

11. Onyshchenko, I.; Yu Nikiforov, A.; De Geyter, N.; Morent, R. Local analysis of PET surface functionalization by an atmospheric pressure plasma jet. Plasma Process. Polym. 2015, 12, 466-476. [CrossRef]

12. Nishime, T.M.C.; Wagner, R.; Kostov, G.K. Study of modified area of polymer samples exposed to a He atmospheric pressure plasma jet using different treatment conditions. Polymers 2020, 12, 1028. [CrossRef] [PubMed]

13. Ellerweg, D.; Benedikt, J.; von Keudell, A.; Knake, N.; Schulz-von der Gathen, V. Characterization of the effluent of a $\mathrm{He} / \mathrm{O}_{2}$ microscale atmospheric pressure plasma jet by quantitative molecular beam mass spectrometry. New J. Phys. 2010, 12, 013021. [CrossRef]

14. Sousa, J.S.; Niemi, K.; Cox, L.J.; Algwari, Q.T.; Gans, T.; O'Connell, D. Cold atmospheric pressure plasma jets as sources of singlet delta oxygen for biomedical applications. J. Appl. Phys. 2011, 109, 123302. [CrossRef]

15. Reuter, S.; Niemi, K.; Schulz-von der Gathen, V.; Döbele, H.F. Generation of atomic oxygen in the effluent of an atmospheric pressure plasma jet. Plasma Sources Sci. Technol. 2009, 18, 015006. [CrossRef]

16. Reuter, S.; Winter, J.; Schmidt-Bleker, A.; Schroeder, D.; Lange, H.; Knake, N.; Schulz-von der Gathen, V.; Weltmann, K.D. Atomic oxygen in a cold argon plasma jet: TALIF spectroscopy in ambient air with modelling and measurements of ambient species diffusion. Plasma Sources Sci. Technol. 2012, 21, 024005. [CrossRef]

17. Jiang, J.; Luo, Y.; Moldgy, A.; Aranda Gonzalvo, Y.; Bruggeman, P.J. Absolute spatially and time-resolved O, $\mathrm{O}_{3}$, and air densities in the effluent of a modulated RF-driven atmospheric pressure plasma jet obtained by molecular beam mass spectrometry. Plasma Process. Polym. 2019, e1900163. [CrossRef]

18. Schröter, S.; Wijaikhum, A.; Gibson, A.R.; West, A.; Davies, H.L.; Minesi, N.; Dedrick, J.; Wagenaars, E.; de Oliveira, N.; Nahon, L.; et al. Chemical kinetics in an atmospheric pressure helium plasma containing humidity. Phys. Chem. Chem. Phys. 2018, 20, 24263-24286. [CrossRef]

19. Fuh, C.A.; Clark, S.M.; Wu, W.; Wang, C. Electronic ground state $\mathrm{OH}(\mathrm{X})$ radical in a low-temperature atmospheric pressure plasma jet. J. Appl. Phys. 2016, 120, 163303. [CrossRef]

20. Sushkov, V.; Herrendorf, A.-P.; Hippler, R. Metastable argon atom density in complex argon/acetylene plasmas determined by means of optical absorption and emission spectroscopy. J. Phys. D Appl. Phys. 2016, 49, 425201. [CrossRef]

21. Birer, Ö. Reactivity zones around an atmospheric pressure plasma jet. Appl. Surf. Sci. 2015, 354, 420-428. [CrossRef]

22. Nikiforov, A.Y.; Sarani, A.; Leys, C. The influence of water vapor content on electrical and spectral properties of an atmospheric pressure plasma jet. Plasma Sources Sci. Technol. 2011, 20, 015014. [CrossRef]

23. Sarani, A.; Nikiforov, A.Y.; Leys, C. Atmospheric pressure plasma jet in $\mathrm{Ar}$ and $\mathrm{Ar} / \mathrm{H}_{2} \mathrm{O}$ mixtures: Optical emission spectroscopy and temperature measurements. Phys. Plasmas 2010, 17, 063504. [CrossRef]

24. Park, H.S.; Kim, S.J.; Joh, H.M.; Chung, T.H.; Bae, S.H.; Leem, S.H. Optical and electrical characterization of an atmospheric pressure microplasma jet with a capillary electrode. Phys. Plasmas 2010, 17, 033502. [CrossRef]

25. Olabanji, O.T.; Bradley, J.W. Side-on surface modification of polystyrene with an atmospheric pressure microplasma jet. Plasma Process. Polym. 2012, 9, 929-936. [CrossRef]

26. Dowling, D.P.; O’Neill, F.T.; Langlais, S.J.; Law, V.J. Influence of DC pulsed atmospheric pressure plasma jet processing conditions on polymer activation. Plasma Process. Polym. 2011, 8, 718-727. [CrossRef] 
27. Fricke, K.; Duske, K.; Quade, A.; Nebe, B.; Schroder, K.; Weltmann, K.-D.; von Woedtke, T. Comparison of nonthermal plasma processes on the surface properties of polystyrene and their impact on cell growth. IEEE Trans. Plasma Sci. 2012, 40, 2970-2979. [CrossRef]

28. Vesel, A.; Zaplotnik, R.; Kovac, J.; Mozetic, M. Initial stages in functionalization of polystyrene upon treatment with oxygen plasma late flowing afterglow. Plasma Sources Sci. Technol. 2018, 27, 094005. [CrossRef]

29. Vesel, A. Modification of polystyrene with a highly reactive cold oxygen plasma. Surf. Coat. Technol. 2010, 205, 490-497. [CrossRef]

30. Vesel, A.; Primc, G.; Zaplotnik, R.; Mozetič, M. Applications of highly non-equilibrium low-pressure oxygen plasma for treatment of polymers and polymer composites on an industrial scale. Plasma Phys. Control. Fusion 2020, 62, 024008. [CrossRef]

(C) 2020 by the authors. Licensee MDPI, Basel, Switzerland. This article is an open access article distributed under the terms and conditions of the Creative Commons Attribution (CC BY) license (http://creativecommons.org/licenses/by/4.0/). 